\title{
The Safety and Efficacy of Transcutaneous Nerve Stimulation (TENS) in Reducing Vaginal Delivery Labor Pain: Randomized Controlled Clinical Trial
}

\author{
Hanan A. A. Farra, Hatem S. Shalaby, Ahmed A. Fahmy, Maii Nawara \\ Department of Obstetrics and Gynecology, Ain Shams University, Cairo, Egypt \\ Email: maii_nawara@hotmail.com
}

How to cite this paper: Farra, H.A.A., Shalaby, H.S., Fahmy, A.A. and Nawara, M. (2020) The Safety and Efficacy of Transcutaneous Nerve Stimulation (TENS) in Reducing Vaginal Delivery Labor Pain: Randomized Controlled Clinical Trial. Open Journal of Obstetrics and Gynecology, 10, 657-670.

https://doi.org/10.4236/ojog.2020.1050059

Received: April 14, 2020

Accepted: May 8, 2020

Published: May 11, 2020

Copyright $\odot 2020$ by author(s) and Scientific Research Publishing Inc. This work is licensed under the Creative Commons Attribution International License (CC BY 4.0).

http://creativecommons.org/licenses/by/4.0/

\begin{abstract}
Background: Labor analgesia remains the center of interest for both obstetricians and women. The safety of the traditional pharmacologic analgesics remains questionable due to their potential fetal and maternal complications. Therefore, several non-pharmacological modalities were evaluated for their safety and efficacy to relieve labor pain. Among these methods, transcutaneous nerve stimulation (TENS) gained much concern due to ease of use, low cost and high capacity for women self-titration. The study aims to investigate the efficacy of TENS in reducing labor pain associated with vaginal deliveries, and to determine the factors controlling the response to TENS. Methods: The study was a randomized, controlled clinical trial. A total of 390 women candidates for vaginal delivery were randomly allocated to 3 groups of intervention: paracetamol infusion, TENS, and intramuscular pethidine (130 women per group). The primary endpoint was pain intensity assessed on 10-point VAS scale and women satisfaction. Secondary endpoints included maternal or fetal complications. Results: VAS scores recorded during vaginal deliveries demonstrated a statistically significant reduction in TENS group compared to paracetamol at 15, 30 minutes, 1 and 2 hours, while pethidine arm demonstrated lower scores than TENS group $(\mathrm{p}<0.001)$. The intermediate analgesic efficacy of TENS was preserved when evaluating episiotomy related pain scores. Analysis of differences between good and poor responders to TENS indicated that weight, BMI, education level and the stimulation characteristics were statistically different between the two subgroups $(\mathrm{p}<0.001)$. Adverse maternal and fetal outcomes in TENS arm were comparable to paracetamol and significantly less than pethidine. Conclusion: TENS is a reliable labor pain analgesic with comparable efficacy and superior safety relative to pethidine. Clinicians should personalize TENS therapy according to women's
\end{abstract}


BMI and education level for optimized pain control.

\section{Keywords}

Transcutaneous Nerve Stimulation, Vaginal Delivery, Labor Pain

\section{Introduction}

Pain during labor is one of the most painful experiences that women could attain throughout the life. Several obstetric and fetal adverse effects may arise during the vaginal delivery without adequate pain control including neuroendocrine dysregulation, fetal bradycardia and vaginal tears [1]. Additionally, inefficient analgesia during labor contributes to increased requests for cesareans [2]. In Egypt, the estimated rate of C-sections was about $40 \%$ of deliveries which is much higher than the ideal rates accepted by WHO ranging between $10 \%-15 \%$ [3]. Therefore, the introduction of pain relief strategies comprises a paramount importance. Beyond the physiological modifiers, labor pain is influenced by many cultural and psychosocial factors [4]. The multidimensionality of pain perception resulted in considering the women self-assessment to labor analgesia is the gold standard in assessing the efficacy of different analgesics, and shifted the process of labor analgesia to patient-centered care with both clinical and humanistic outcomes [5]. The traditional modalities of labor pain relief depend on pharmacologic agents including opioids and non-steroidal anti-inflammatory drugs (NSAIDs). Due to the association with dose-dependent adverse effects, the drug-centered analgesia has limited patient self-titration and less flexible schedules. Paracetamol is a COX-III inhibitor with the advantage of high tolerability, safety and low costs. Nevertheless, the efficacy of paracetamol in reducing labor pain associated with vaginal deliveries is still controversial [6]. On the contrary, Pethidine is an opioid analgesic with better efficacy compared to paracetamol; however, the application of pethidine in labor is limited by its adverse effects including fetal and maternal bradycardia and respiratory depression [7]. The limitations of drug therapy structured the way for safer and possibly more effective non-pharmacologic therapies including yoga, acupuncture, acupressure, massage therapy, music therapy and transcutaneous nerve stimulation (TENS) [8]. Among the proposed non-pharmacologic analgesia, TENS has gained much concern due to the available evidence of efficacy, safety and tolerability [9]. The principle of using TENS depends on delivering a low-intensity electric current through the skin surface, resulting in blockade of nociceptive transmission to CNS with associated stimulation of descending inhibitory pathways of pain, a mechanism consistent with the pain gate theory. It has been previously tested in treatment of various conditions such as low back pain, arthritic pain, neurogenic pain and postsurgical pain. The device is a battery-powered unit that delivers electrical impulses through electrodes applied over the desired site [10]. So far, 
the evidence of the application of TENS as a labor analgesic strategy is sparse [11]. Additionally, the factors affecting the individual analgesic response to TENS are unclear.

The current study aims to investigate for the safety and efficacy of TENS in vaginal deliveries compared to the traditional pharmacologic strategies including paracetamol and pethidine; and identification of the specific factors controlling the response to TENS analgesia.

\section{Methods}

\subsection{Study Design}

The study was open label, randomized controlled clinical trial. Prior to enrollment in the study, informed consent was taken from each participant. The study was approved by the ethical committee of the faculty of medicine, Ain Shams University, Cairo Egypt. The study follows the percepts of Helsinki Declaration, and agrees with good clinical practice guidelines. Women allocation to either TENS, pethidine, or paracetamol (control) arms was facilitated by computer-aided random number generation. Due to the apparent differences between drug-related and TENS related interventions, blindness was not possible at the level of the current study.

\subsection{Patients}

Pregnant women who are candidates to vaginal delivery were admitted to Ain Shams Maternity hospital between January 2018 and October 2019 were screened for eligibility. Inclusion criteria include maternal age between 20 - 40 years, full-term pregnancy with single fetus vertex presentation in active phase of labor. Active phase of labor was defined as cervical dilatation of $3 \mathrm{~cm}$ or more, cervical effacement of $60 \%$ or more, and good uterine contractions. Excluded women include contraindication to vaginal delivery, history of liver disease, hypersensitivity to paracetamol or pethidine, or women presented with implantable cardioverter devices (ICDs) or pacemakers. Candidates from each study arm were allowed to withdraw once intolerance to the underlying intervention was reported.

Data collected from each case include maternal age, weight, height, body mass index, educational level, parity, gestational age, need for labor augmentation and overall satisfaction with the analgesic strategy. Neonatal data collected postpartum includes 1-minute and 5-minute Apgar scores.

\subsection{Treatment}

For the paracetamol group, women received 1gm (Perfalgan ${ }^{\oplus}$; paracetamol, Bristol Mayers, France) diluted in $100 \mathrm{ml}$ saline and infused over 15 minutes. Dose titrations were allowed as $1 \mathrm{gm}$ increments every 6 hours for each case to a maximum of 4 grams. For the pethidine group, women were infused with an empirical dose of $50 \mathrm{mg}$ (Pethidine hydrochloride $50 \mathrm{mg}$ ampule, Roche Pharmaceuticals, Egypt) diluted in $10 \mathrm{ml}$ saline over 10 minutes. Repeated doses of 
pethidine were permitted in a 4 hour interval without incremental increase. Finally, women allocated to TENS group had lateral placement of the electrodes on either side of the spine at the region between T10 to L1 and S1 to S4. Frequency and current intensity will be escalated to adequate pain control. Empirically, women of TENS arm will receive a 30-minute stimulation when starting in the active phase of labor (cervical dilatation of $4 \mathrm{~cm}$ or more). The duration of stimulation will be increased thereafter to adequate analgesia. TENS was delivered using Prorelax ${ }^{\oplus}$ device (Zubehör, Germany). The delivered waveforms had frequency between 15 - $70 \mathrm{~Hz}$; pulse width 156 - $260 \mu \mathrm{s}$, the current intensity escalated between 19 - $25 \mathrm{~mA}$ to adequate pain control. The current frequency and intensity were allowed to vary in an escalating way to avoid muscular accommodation to fixed monotonous impulses, and to maintain a tolerable stimulation.

\subsection{Outcomes}

The primary outcomes were pain intensity assessed during labor and after episiotomy cutting procedure. Perceived pain was evaluated using a 10-point VAS score. Women were asked to mark scores between 0 - 3 if they experienced mild pain, 4 - 6 for moderate pain and 7 - 10 for severe pain. Pain scores were recorded at the start of the active phase of labor (baseline), 15, 30 minutes, 1 and 2 hours later. For those who underwent episiotomy cutting, scores were recorded before, immediately after, 30 minutes, 1, 6 and 12 hours following the procedure. Additionally, a one-question survey was asked for each candidate on follow up to determine the overall satisfaction with her analgesic strategy. Women were asked to choose a satisfaction level between "very unsatisfied", "unsatisfied", "Neutral", "Satisfied" or "Very satisfied".

The secondary outcomes evaluated were the maternal adverse effects including nausea, vomiting and respiratory depression. Neonatal outcomes were evaluated by assessment of 1-minute and 5-minute APGAR scores, and fetal bradycardia rates.

\subsection{Sample Size Estimation \& Statistical Analysis}

Since the minimum clinically significant VAS reduction in using TENS pain management was $1.3 \mathrm{~cm}$ [12], it was hypothesized that the effect size was 0.4 is sufficient to detect the difference between TENS group and control VAS scores. Considering prior alpha of 0.05 and power of $80 \%$, the calculated sample size based on pairwise one-way ANOVA formula was 112 women per study arm. To account for difficulties, misconduct of pain assessment procedures or possible withdrawals, the final sample size was set to 130 women per study arm. Continuous data were evaluated for normality using Shapiro Wilk test. Parametric data were summarized as mean \pm SD. Nonparametric data including VAS scores presented as median (range). Nominal variables described as number and percentage. Kruskal Wallis ANOVA was used for non-parametric comparison of 
pain scores among the study groups, while one-way ANOVA was applied for parametric hypothesis testing. Chi-square test was applied for comparing proportions of nominal data. $P$ values of less than 0.05 were considered statistically significant. Sample size calculation was performed using R packages (R Foundation for Statistical Computing, Vienna, Austria), and the rest of the statistical analysis was done using SPSS for Windows (version 24.0, IBM Corp Armonk, NY, USA).

\section{Results}

A total of 409 pregnant women were recruited, 390 were included in the final analysis after allocation to pethidine group $(\mathrm{n}=130)$, paracetamol group $(\mathrm{n}=$ $130)$ and TENS group $(n=130)$. Nineteen cases were excluded due to refusal to sign the informed consent, contraindication to the medication, loss of follow up or discontinuation of analgesic therapy. An outline of the study flow chart is provided in Figure 1.

Comparing demographic and clinical characteristics among the study groups.

The study arms showed equivalent distribution of age, weight, height, body mass index, educational level, parity, gestational age and duration of labor with no statistical significance ( $p>0.05$ ) observed when comparing the baseline characteristics of each arm of the study (Table 1).

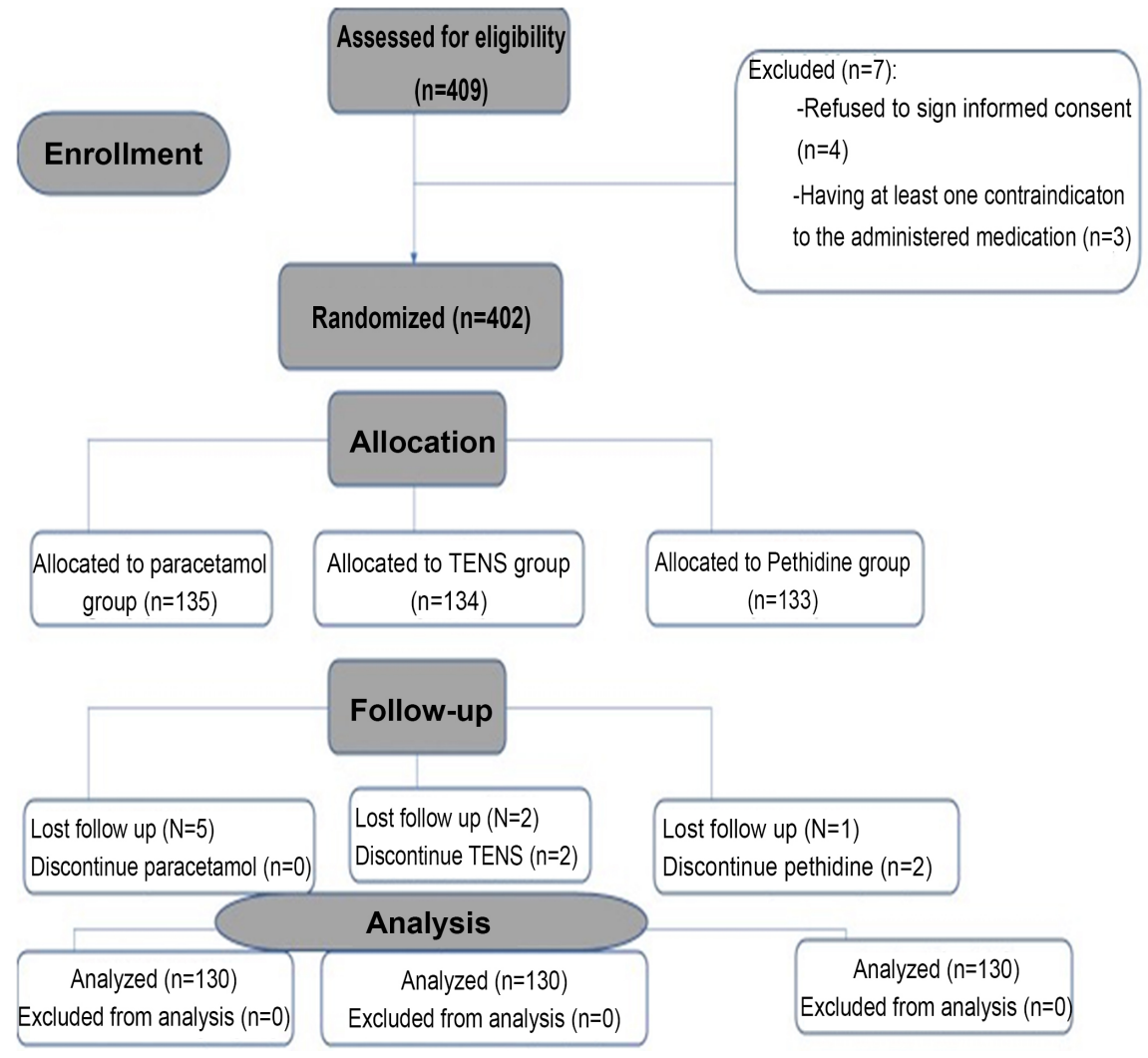

Figure 1. Study flow chart. 


\section{Comparing Labor pain profiles.}

No significant differences were observed in VAS pain scores prior to the analgesic intervention $(\mathrm{p}=0.45)$. However, the longitudinal evaluation of pain intensity over time showed a statistically significant lower pain scores in TENS arm compared to paracetamol, while higher scores than pethidine. The intermediate analgesic efficacy of TENS was retained longitudinally after 15, 30 minutes, 1 and 2 hours (Table 2). The need for additional analgesia follows the same trend with 28 cases in the paracetamol group, 12 cases in TENS group and only 2 cases in pethidine arm $(\mathrm{p}<0.001)$. Similarly, the need for labor augmentation was highest in the paracetamol group (21.5\%), while lowest in pethidine arm (1.5\%).

\section{Comparing episiotomy pain profiles}

Episiotomy cutting was performed in 70 women $(53.8 \%)$ of the paracetamol group, 62 (47.7\%) of TENS group and 78 (60\%) of the pethidine group. Despite the slight decrease in pain scores of TENS arm at baseline $(p=0.003)$, all groups demonstrated the same median VAS score at baseline (median VAS score for the three arms was 8). Longitudinal assessment of episiotomy related pain at the end of episiotomy cutting, after 30 minutes, after 1, 6 and 12 hours demonstrated statistically significant lower VAS scores in TENS group compared to paracetamol, while higher scores compared to pethidine; a similar pattern of pain profiles that have been observed previously with labor pain. Table 3 summarizes the differences in episiotomy pain scores among the study groups.

Factors affecting response to TENS:

Table 1. Comparing demographic and clinical characteristics among the study groups $(n=390)$.

\begin{tabular}{|c|c|c|c|c|}
\hline Variable & $\begin{array}{l}\text { Paracetamol group } \\
\qquad(\mathrm{n}=130)\end{array}$ & $\begin{array}{l}\text { TENS group } \\
(\mathrm{n}=130)\end{array}$ & $\begin{array}{l}\text { Pethidine group } \\
\quad(n=130)\end{array}$ & $\mathrm{p}$-value \\
\hline Maternal age (years) & $23.23 \pm 4.43$ & $24.18 \pm 4.57$ & $23.75 \pm 4.26$ & $0.226^{*}(\mathrm{NS})$ \\
\hline Weight (Kg) & $73.98 \pm 21.77$ & $76.63 \pm 20.26$ & $72.35 \pm 15.32$ & $0.197^{\star}(\mathrm{NS})$ \\
\hline Height (m) & $1.61 \pm 0.17$ & $1.63 \pm 0.167$ & $1.62 \pm 0.165$ & $0.619^{\star}(\mathrm{NS})$ \\
\hline Body mass index $\left(\mathrm{Kg} / \mathrm{m}^{2}\right)$ & $28.18 \pm 6.14$ & $28.76 \pm 5.8$ & $27.92 \pm 4.5$ & $0.45^{\star}(\mathrm{NS})$ \\
\hline \multicolumn{5}{|l|}{ Education level (n, \%) } \\
\hline Illiterate & $17(13.1 \%)$ & $19(14.6 \%)$ & $19(14.6 \%)$ & \multirow{4}{*}{$0.315^{* *}(\mathrm{NS})$} \\
\hline Primary education & $28(21.5 \%)$ & $35(26.9 \%)$ & $43(33.1 \%)$ & \\
\hline Secondary education & $50(38.5 \%)$ & $39(30 \%)$ & $33(25.4 \%)$ & \\
\hline University/Postgraduate & $35(26.9 \%)$ & $37(28.5 \%)$ & $35(26.9 \%)$ & \\
\hline Parity (median, range) & $2(0-5)$ & $2(0-5)$ & $2(0-5)$ & $0.34^{*}(\mathrm{NS})$ \\
\hline Gestational age (months) & $38.66 \pm 0.81$ & $38.72 \pm 0.8$ & $38.74 \pm 0.74$ & $0.71^{*}(\mathrm{NS})$ \\
\hline \multicolumn{5}{|l|}{ Labor duration (minutes) } \\
\hline 1 st stage & $252.1 \pm 82.73$ & $255.96 \pm 85.42$ & $255.38 \pm 96.48$ & $0.93^{*}(\mathrm{NS})$ \\
\hline 2nd stage & $23.12 \pm 7.72$ & $21.87 \pm 6.99$ & $23.5 \pm 7.91$ & $0.192^{*}$ (NS) \\
\hline 3rd stage & $10.91 \pm 3.3$ & $10.96 \pm 2.93$ & $11.35 \pm 3.42$ & $0.49^{*}(\mathrm{NS})$ \\
\hline
\end{tabular}

${ }^{\star}$ Kruskal Wallis ANOVA test was used for estimation of $\mathrm{p}$ value. ${ }^{\star \star}$ Chi-square test was used for comparison. NA: not applicable, NS: non-significant, S: Significant, SD: standard deviation, TENS: transcutaneous electric nerve stimulation. 
Table 2. Impact of different analgesic strategies on labor pain.

\begin{tabular}{ccccc}
\hline Pain characteristic & $\begin{array}{c}\text { Paracetamol group } \\
(\mathrm{n}=130)\end{array}$ & $\begin{array}{c}\text { TENS group } \\
(\mathrm{n}=130)\end{array}$ & $\begin{array}{c}\text { Pethidine group } \\
(\mathrm{n}=130)\end{array}$ & p-value $^{*}$ \\
\hline Baseline & $7(5-9)$ & $7(4-9)$ & $7(5-9)$ & $0.45(\mathrm{NS})$ \\
After 15 min & $7(5-9)$ & $6(4-8)$ & $5(4-9)$ & $<0.001(\mathrm{~S})$ \\
After 30 min & $7(5-9)$ & $5(4-9)$ & $4(3-7)$ & $<0.001(\mathrm{~S})$ \\
After 1 hour & $6(5-9)$ & $5(4-9)$ & $4(3-7)$ & $<0.001(\mathrm{~S})$ \\
$\begin{array}{c}\text { After 2 hours } \\
\text { Need for additional } \\
\text { analgesia (n, \%) }\end{array}$ & $6(5-9)$ & $5(4-8)$ & $4(3-7)$ & $<0.001(\mathrm{~S})$ \\
$\begin{array}{l}\text { Labor augmentation } \\
\text { with oxytocin (n, \%) }\end{array}$ & $28(21.5 \%)$ & $9(6.9 \%)$ & $2(1.5 \%)$ & $<0.001^{\star *}(\mathrm{~S})$ \\
\hline
\end{tabular}

${ }^{\star}$ Kruskal Wallis ANOVA test was used for comparison. ${ }^{* *}$ Chi-square test was applied in $\mathrm{p}$ value calculation. NS: non-significant, S: Significant.

The overall satisfaction of pain control using TENS assessed by patient question was intermediate between paracetamol and pethidine (Figure 2). Based on women satisfaction, TENS arm was further classified into good responders $(\mathrm{n}=$ 72) including subjects who reported high or very high satisfaction with pain control, and poor responders whose satisfaction was neutral or lower $(n=58)$. Comparing both groups, maternal weight, body mass index and need for labor augmentation were lower in good responders' group ( $<<0.001, \mathrm{p}<0.001$ and 0.005 ; respectively), while the educational level was statistically higher in good responders' group $(\mathrm{p}<0.001)$. Maternal age, height, parity and gestational age failed to demonstrate statistical significance Table 4.

\section{Maternal Outcomes:}

TENS group demonstrated the lowest adverse effects rate compared to paracetamol and pethidine. Nausea was experienced in 16 women of TENS group compared to 23 and 34 women in paracetamol and pethidine respectively ( $\mathrm{p}=$ 0.016). Similarly, vomiting was presented in only 4 women in TENS arm compared to 11 and 20 women in paracetamol and pethidine respectively $(\mathrm{p}=$ 0.002). No cases of respiratory depression were observed in both paracetamol or TENS arm with 3 cases in the pethidine group; however, this difference was not statistically significant $(\mathrm{p}=0.49)$. Differences in adverse effects profile among the study groups were summarized in Table 5 .

\section{Neonatal outcomes:}

Fetal bradycardia rate was non-significantly lower in TENS arm (2.31\%) compared to the other arms $(\mathrm{p}=0.77)$. Moreover, Apgar scores by 1 and $5 \mathrm{mi}-$ nutes after birth were similar ( $\mathrm{p}=0.87,0.71$; respectively). Neonatal outcomes are presented in Table 6 .

\section{Discussion}

The current work structures evidence about the intrinsic analgesic effectiveness 


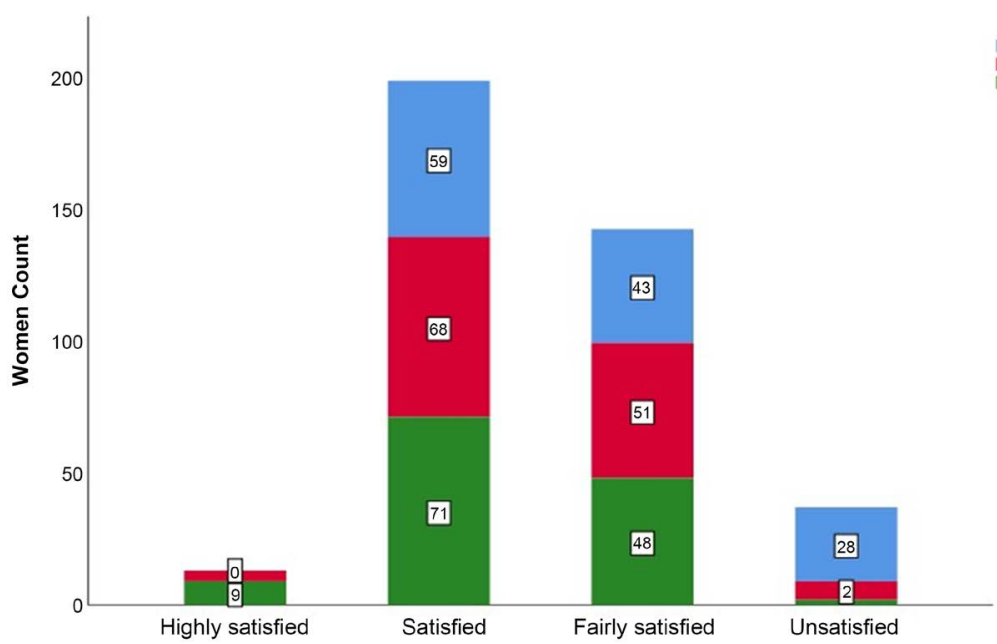

Figure 2. Satisfaction with labor analgesia.

Table 3. Impact of different analgesic strategies on episiotomy pain.

\begin{tabular}{ccccc}
\hline Episiotomy characteristics & $\begin{array}{c}\text { Paracetamol group } \\
(\mathbf{n}=130)\end{array}$ & $\begin{array}{c}\text { TENS group } \\
(\mathbf{n}=130)\end{array}$ & $\begin{array}{c}\text { Pethidine group } \\
(\mathbf{n}=130)\end{array}$ & p-value \\
\hline Episiotomy cutting (n, \%) & $70(53.8 \%)$ & $62(47.7 \%)$ & $78(60 \%)$ & $0.138^{*}(\mathrm{NS})$ \\
Baseline & $8(7-10)$ & $8(5-10)$ & $8(6-10)$ & $0.003^{* *}(\mathrm{~S})$ \\
End of episiotomy & $6(4-7)$ & $4(3-6)$ & $4(2-7)$ & $<0.001^{* *}(\mathrm{~S})$ \\
After 30 min & $3.5(2-6)$ & $3(2-7)$ & $3(1-5)$ & $0.002^{* *}(\mathrm{~S})$ \\
After 1 hour & $3(2-6)$ & $3(2-5)$ & $2(1-5)$ & $<0.001^{* *}(\mathrm{~S})$ \\
After 6 hours & $3(1-6)$ & $2(1-5)$ & $1(0-4)$ & $<0.001^{* *}(\mathrm{~S})$ \\
After 12 hours & $2(0-4)$ & $1(0-2)$ & $0(0-2)$ & $<0.001^{* *}(\mathrm{~S})$ \\
\hline
\end{tabular}

${ }^{\star}$ Chi square test was used for comparison. ${ }^{\star}$ Kruskal Wallis ANOVA test was used for comparison. NS: non-significant, S: Significant.

Table 4. Comparing good versus poor respondents to TENS stimulation.

\begin{tabular}{cccc}
\hline Response & $\begin{array}{c}\text { Good response } \\
(\mathbf{n}=72)\end{array}$ & $\begin{array}{c}\text { Poor response } \\
(\mathbf{n}=58)\end{array}$ & p-value \\
\hline Maternal Age (years) & $24.33 \pm 3.78$ & $24.17 \pm 4.43$ & $0.82^{\star}(\mathrm{NS})$ \\
Weight (Kg) & $68.5 \pm 17.73$ & $86.72 \pm 18.7$ & $<0.001^{*}(\mathrm{~S})$ \\
Height (m) & $1.61 \pm 0.162$ & $1.66 \pm 0.17$ & $0.085^{*}(\mathrm{NS})$ \\
Body mass index (Kg/m $\left.{ }^{2}\right)$ & $26.67 \pm 6.34$ & $31.37 \pm 3.67$ & $<0.001^{*}(\mathrm{~S})$ \\
Education level & $3(1-4)$ & $2(1-3)$ & $<0.001^{* *}(\mathrm{~S})$ \\
Parity & $3(0-5)$ & $2(1-4)$ & $0.836^{*}(\mathrm{NS})$ \\
Gestational age (months) & $38.95 \pm 0.83$ & $38.89 \pm 0.75$ & $0.054^{*}(\mathrm{NS})$ \\
Labor induction with oxytocin (n, \%) & $2(2.8 \%)$ & $10(17.2 \%)$ & $\mathbf{0 . 0 0 5 ^ { * * } ( \mathrm { S } )}$ \\
Current intensity & $12.33 \pm 2.2$ & $17.83 \pm 1.74$ & $<0.001^{*}(\mathrm{~S})$ \\
Current duration & $109.15 \pm 43.84$ & $233.95 \pm 90.92$ & $<0.001^{*}(\mathrm{~S})$ \\
\hline
\end{tabular}

${ }^{*}$ Mann-Whitney $\mathrm{U}$ test was used for estimation of $\mathrm{p}$ value. ${ }^{*}$ Chi-square test was used for comparison. NS: non-significant \& S: Significant. 
Table 5. Impact of different analgesic strategies on maternal hemodynamics.

\begin{tabular}{ccccc}
\hline Adverse outcome & $\begin{array}{c}\text { Paracetamol group } \\
(\mathrm{n}=130)\end{array}$ & $\begin{array}{c}\text { TENS group } \\
(\mathrm{n}=130)\end{array}$ & $\begin{array}{c}\text { Pethidine group } \\
(\mathrm{n}=130)\end{array}$ & p-value $^{*}$ \\
\hline Nausea (n, \%) & $23(17.7 \%)$ & $16(12.3 \%)$ & $34(26.2 \%)$ & $\mathbf{0 . 0 1 6 ( \mathrm { S } )}$ \\
Vomiting (n, \%) & $11(8.5 \%)$ & $4(3.1 \%)$ & $20(15.4 \%)$ & $\mathbf{0 . 0 0 2 ( \mathrm { S } )}$ \\
Respiratory depression (n, \%) & $0(0 \%)$ & $0(0 \%)$ & $3(2.3 \%)$ & $0.49(\mathrm{NS})$ \\
\hline
\end{tabular}

${ }^{*}$ Chi-square test was used for comparison. NS: non-significant \& S: Significant.

Table 6. Neonatal outcomes in different study groups.

\begin{tabular}{ccccc}
\hline Neonatal characteristics & $\begin{array}{c}\text { Paracetamol group } \\
(\mathbf{n}=130)\end{array}$ & $\begin{array}{c}\text { TENS group } \\
(\mathrm{n}=130)\end{array}$ & $\begin{array}{c}\text { Pethidine group } \\
(\mathbf{n}=130)\end{array}$ & P-value* \\
\hline Fetal bradycardia $(\mathrm{n}, \%)^{*}$ & $4(3.08 \%)$ & $3(2.31 \%)$ & $5(3.85 \%)$ & $0.77(\mathrm{NS})$ \\
APGAR score after 1 min $^{* *}$ & $7(4-9)$ & $7(4-9)$ & $7(4-9)$ & $0.87(\mathrm{NS})$ \\
APGAR score after 5 min $^{* *}$ & $8(6-10)$ & $8(6-10)$ & $8(6-10)$ & $0.71(\mathrm{NS})$ \\
5-min APGAR score $<7$ (n, \%)* & $11(8.5 \%)$ & $15(11.5 \%)$ & $9(6.9 \%)$ & $0.42(\mathrm{NS})$ \\
\hline
\end{tabular}

${ }^{*}$ Chi-square test was used for comparison. ${ }^{*}$ Kruskal Wallis ANOVA test was used for comparison. NS: non-significant.

of TENS in reducing labor pain. Previous studies reported the analgesic value of electrostimulation either alone or in combination with patient controlled epidural analgesia (PCEA) [13] [14]. The application of electric current using TENS is hypothesized to suppress the pain signals through inhibition of peripheral transmission of nociceptive information to the brain and by stimulation of the local release of endorphins and encephalins [11]. In rat model, Jiang et al. recently highlighted the potential impact of electric stimulation in reducing serum levels of PGE2 and myometrial expression of PGE2 receptors; an important mediator of uterine contraction during labor [15]. Through the present study, the analgesic properties of TENS compared to traditional pharmacologic analgesia together with the determinants of the women response to stimulation were investigated.

The key finding of the present study is that TENS exhibits an intermediate analgesic characteristic for labor pain when compared to pethidine and paracetamol. TENS was found to be superior over paracetamol, while inferior to pethidine. Similar findings were reported by Shahoei et al. conducted a randomized controlled clinical trial involving 90 nulliparous pregnant women and found that TENS do have statistically significant lower pain scores that are sustained during the first and second stages of labor and 4 hours after delivery [16]. Santana et al. concluded that TENS may result in statistically significant lower pain scores together with a delayed need for additional analgesia [12]. A meta-analysis of 9 trials including 1076 pregnant women concluded that TENS may result in a significant reduction of labor pain with reduced need for additional analgesia [17]. Peng et al. reported more than $25 \%$ reduction in pain intensity in $68.6 \%$ of TENS group compared to control [18]. In contrast to our results, a recent me- 
ta-analysis concluded that pethidine when compared to TENS failed to demonstrate additional reduction in VAS score or higher women satisfaction [19]. Electric stimulation failed to demonstrate significant reduction in labor pain VAS score when compared to no stimulation [20]. Nevertheless, this discrepancy should be interpreted based on technique differences. Mucuk and Baser applied electro-acupuncture involving both pressure and electric stimulation, different placement of electrodes and smaller sample size $(n=40)$.

Similar patterns of pain management were observed in women undergoing episiotomy cutting. Compared to the paracetamol control group, a significant reduction of VAS pain scores was attained at the end of episiotomy, after $30 \mathrm{mi}-$ nutes, 1, 6, and 12 hours following episiotomy. Despite that this could be confounded by the statistically significant difference among the study group median scores at baseline assessment ( $p=0.003)$, it should be noted that this effect is minimal; due to similar median pain scores presented at baseline for the three study groups (median VAS $=8$ ). Additionally, it was previously suggested that the minimum clinically meaningful difference in mean VAS is $1.3 \mathrm{~cm}$, which is much larger than presented in baseline assessment [11] [21]. Our results replicate the findings of Rezaeyan et al. who reported a significant reduction of episiotomy related pain in TENS group when compared to lidocaine when assessed at 1, 6 and 12 hours compared to lidocaine. They reported a non-significant reduction of pain scores at the end of episiotomy; however, this discrepancy may be attributed to their relatively small sample size $(n=40)$ [22].

Analysis of differences in clinical and socioeconomic characteristics between TENS good and poor responders in our analysis concluded that TENS response may be modified by TENS characteristics, obesity and women education may be the key players in response to TENS. In their double-blinded randomized clinical trial, Báez Suárez et al. included 63 pregnant candidates randomized to receive constant, escalating stimulation dose or placebo. They reported statistically significant lower VAS scores and higher satisfaction with women received higher doses of TENS stimulation. It should be noted that the site of placement of TENS electrodes is crucial. Optimally, electrodes are connected at T10-L1 and S2-S4 where the spinal centers implicated in labor pain transmission are most affected [11].

We found a statistically higher educational level in the good response group. However, this point should be interpreted with caution; as the difference likely attributed to differences in understanding the procedures of pain reporting rather than a true difference in pain profiles.

Maternal age was previously reported as a factor that adds to TENS analgesic response; principally due to higher placebo effects at higher women age [23].

Nevertheless, this result couldn't be replicated in our results; possibly due to the limited age span in our study group secondary to inclusion of women of childbearing age only.

Since body fats may impede the transcutaneous electric flow [24], it was not surprising that good responders to TENS stimulation presented with statistically 
significant lower weight and body mass index ( $\mathrm{p}<0.001$ for both variables). To best of our knowledge, this point has not been addressed yet in relevant studies assessing labor pain. Generally, understanding the factors controlling response to TENS helps obstetricians to individualize and optimize TENS therapy for maximizing pain control. For example, if TENS is planned for an obese woman, clinicians should apply higher current intensities with longer duration and more frequent stimulation for optimal pain management, with much focus on patient education about reporting the perceived pain.

Assessment of maternal adverse effects profiles revealed a statistically lower rate of nausea and vomiting in TENS compared to pethidine. Elbohoty et al. compared intravenous paracetamol to pethidine as labor analgesia and demonstrated significantly higher rates of vomiting in pethidine arm [25]. Mechanistically, opioid-induced nausea and vomiting are related to direct stimulation of chemoreceptor trigger zone (CTZ), or by slowing the gastric emptying, and considered one of the main reasons for opioid therapy discontinuation [26]. Therefore, TENS may provide a much tolerable analgesic option compared to pethidine.

Additionally, our results confirmed the fetal safety of TENS during labor. We found no statistically significant differences in 1-, 5-minute Apgar scores or respiratory distress among the study groups. In line with our findings, Santana et al. reported no statistically significant difference between experimental TENS group and control group on the basis of percentage neonates born with Apgar scores less than 7 [12]. In their meta-analysis, Mello et al. reported that TENS was not associated with adverse neonatal outcomes [17].

The study has many points of strength. To best our knowledge, our study included the largest sample size relative to similar reports. In addition, we studied the pain characteristics during both labor and episiotomy procedures. Understanding the differences between good and poor responders of TENS were comprehensively analyzed in the current analysis, facilitating the practical individualization of TENS therapy to candidate women. However, some limitations do exist. The subjectivity of pain assessment and the affection of pain perception by multiple emotional, socioeconomic and cultural factors remains the main limitation of our study and similar ones, making the pain management of TENS are inconclusive.

\section{Conclusion}

TENS seems to have a satisfactory pain reducing properties through the labor. The pain characteristics and woman satisfaction during labor and episiotomy were intermediate; better analgesic than paracetamol, while inferior to pethidine. Nevertheless, the adverse maternal and fetal outcomes of TENS are significantly lower than pethidine. The superior safety profile together with the ease of use, women self-administration, availability and reduced cost make TENS an ideal choice for labor analgesia. 


\section{Conflicts of Interest}

The authors declare no conflicts of interest regarding the publication of this paper.

\section{References}

[1] Hoque, M. (2011) Incidence of Obstetric and Foetal Complications during Labor and Delivery at a Community Health Centre, Midwives Obstetric Unit of Durban, South Africa. International Scholarly Research Notices, 2011, Article ID: 259308. https://doi.org/10.5402/2011/259308

[2] Zheng, H., Zheng, B.-X. and Lin, X.-M. (2020) The Trend of Labor Analgesia in the World and China: A Bibliometric Analysis of Publications in Recent 30 Years. Journal of Pain Research, 13, 517-526. https://doi.org/10.2147/JPR.S232132

[3] Ebrashy, A.-E., Kassab, A., Nada, A., Saleh, W.F. and Soliman, A. (2011) Caesarean Section in a University and General Tertiary Hospitals in Cairo; Egypt: Rates, Indications and Limits. Kasr Al-Aini Journal of Obstetrics and Gynecology, 2, 2026.

[4] Beigi, S., Valiani, M., Alavi, M. and Mohamadirizi, S. (2019) The Relationship between Attitude toward Labor Pain and Length of the First, Second, and Third Stages in Primigravida Women. Journal of Education and Health Promotion, 8, 130. https://doi.org/10.4103/jehp.jehp_4_19

[5] Tan, D.J.A., Sultana, R., Han, N.L.R., Sia, A.T.H. and Sng, B.L. (2018) Investigating Determinants for Patient Satisfaction in Women Receiving Epidural Analgesia for Labour Pain: A Retrospective Cohort Study. BMC Anesthesiology, 18, 50 https://doi.org/10.1186/s12871-018-0514-8

[6] Abdollahi, M.-H., Dareshiri, S. and Mallah, F. (2014) Intravenous Paracetamol versus Intramuscular Pethidine in Relief of Labour Pain in Primigravid Women. Nigerian Medical Journal, 55, 54-57. https://doi.org/10.4103/0300-1652.128167

[7] Omotayo, R., Faturoti, S., Ehinmitan, R. and Alao, F. (2018) Comparison of Intramuscular Paracetamol and Intramuscular Pethidine as Analgesic in the First Stage of Labor. Tropical Journal of Obstetrics and Gynaecology, 35, 348-357. https://doi.org/10.4103/TJOG.TJOG_33_18

[8] Arendt, K.W. and Tessmer-Tuck, J.A. (2013) Nonpharmacologic Labor Analgesia. Clinics in Perinatology, 40, 351-371. https://doi.org/10.1016/j.clp.2013.05.007

[9] Dowswell, T., Bedwell, C., Lavender, T. and Neilson, J.P. (2009) Transcutaneous Electrical Nerve Stimulation (TENS) for Pain Relief in Labour. Cochrane Database of Systematic Reviews, 2, CD007214. https://doi.org/10.1002/14651858.CD007214.pub2

[10] Van der Spank, J.T., Cambier, D.C., De Paepe, H.M.C., Danneels, L.A.G., Witvrouw, E.E. and Beerens, L. (2000) Pain Relief in Labour by Transcutaneous Electrical Nerve Stimulation (TENS). Archives of Gynecology and Obstetrics, 264, 131-136. https://doi.org/10.1007/s004040000099

[11] Báez-Suárez, A., Martín-Castillo, E., García-Andújar, J., García-Hernández, J.Á., Quintana-Montesdeoca, M.P. and Loro-Ferrer, J.F. (2018) Evaluation of Different Doses of Transcutaneous Nerve Stimulation for Pain Relief during Labour: A Randomized Controlled Trial. Trials, 19, 652.

https://doi.org/10.1186/s13063-018-3036-2

[12] Santana, L.S., Gallo, R.B.S., Ferreira, C.H.J., Duarte, G., Quintana, S.M. and Marcolin, A.C. (2016) Transcutaneous Electrical Nerve Stimulation (TENS) Reduces Pain and Postpones the Need for Pharmacological Analgesia during Labour: A Rando- 
mised Trial. Journal of Physiotherapy, 62, 29-34. https://doi.org/10.1016/j.jphys.2015.11.002

[13] Xiao, J., Yi, W. and Wu, L. (2019) Effects of Electroacupuncture on Reducing Labor Pain and Complications in the Labor Analgesia Process of Combined Spinal-Epidural Analgesia with Patient-Controlled Epidural Analgesia. Archives of $G y$ necology and Obstetrics, 299, 123-128.

[14] Li, M.J., Wei, B.X., Deng, Q.X., Liu, X., Zhu, X.D. and Zhang, Y. (2019) Effect of Preemptive Electroacupuncture on Pain Reactions in Primiparousparturients during Vaginal Delivery. Journal of Acupuncture Research, 44, 752-756. https://doi.org/10.1007/s00404-018-4955-6

[15] Jiang, G.X., Jiang, Q.Y., Mo, H.X., Li, L. and Wang, M.Y. (2019) Electroacupuncture for Pain Relief in Labour Inhibits Spinal p38 MAPK-Mediated Prostaglandin E2 Release and Uterine Prostaglandin E2 Receptor Expression in Rats. Acupuncture in Medicine, 37, 116-124.

[16] Shahoei, R., Shahghebi, S., Rezaei, M. and Naqshbandi, S. (2017) The Effect of Transcutaneous Electrical Nerve Stimulation on the Severity of Labor Pain among Nulliparous Women: A Clinical Trial. Complementary Therapies in Clinical Practice, 28, 176-180. https://doi.org/10.1016/j.ctcp.2017.05.004

[17] Mello, L.F.D., Nóbrega, L.F. and Lemos, A. (2011) Estimulaçãoelétricatranscutânea no alívio da dor do trabalho de parto: Revisãosistemática e meta-análise. Revista Brasileira de Fisioterapia, 15, 175-184. https://doi.org/10.1590/S1413-35552011000300002

[18] Peng, T., Li, X.T., Zhou, S.F., Xiong, Y., Kang, Y. and Cheng, H.D. (2010) Transcutaneous Electrical Nerve Stimulation on Acupoints Relieves Labor Pain: A Nonrandomized Controlled Study. Chinese Journal of Integrative Medicine, 16, 234-238. https://doi.org/10.1007/s11655-010-0234-9

[19] Smith, L.A., Burns, E. and Cuthbert, A. (2018) Parenteral Opioids for Maternal Pain Management in Labour. Cochrane Database of Systematic Reviews, 6, 232-234. https://doi.org/10.1002/14651858.CD007396.pub3

[20] Mucuk, S. and Baser, M. (2014) Effects of Noninvasive Electroacupuncture on Labour Pain and Duration. Journal of Clinical Nursing 23, 1603-1610. https://doi.org/10.1111/jocn.12256

[21] Gallagher, E.J., Liebman, M. and Bijur, P.E. (2001) Prospective Validation of Clinically Important Changes in Pain Severity Measured on a Visual Analog Scale. Annals of Emergency Medicine, 38, 633-638. https://doi.org/10.1067/mem.2001.118863

[22] Rezaeyan, M., Geranmayeh, M. and Direkvand-Moghadam, A. (2017) Comparison of Transcutaneous Electrical Nerve Stimulation and Lidocaine on Episiotomy Complication in Primiparous Women: A Randomized Clinical Trial. Iranian Journal of Nursing and Midwifery Research, 22, 26-30. https://doi.org/10.4103/ijnmr.IJNMR_250_15

[23] Daguet, I., Bergeron-Vézina, K., Harvey, M.P., Martel, M. and Léonard, G. (2018) Transcutaneous Electrical Nerve Stimulation and Placebo Analgesia: Is the Effect the Same for Young and Older Individuals? Clinical Interventions in Aging, 13, 335-342. https://doi.org/10.2147/CIA.S152906

[24] Doheny, E.P., Caulfield, B.M., Minogue, C.M. and Lowery, M.M. (2008) The Effect of Subcutaneous Fat Thickness on the Efficacy of Transcutaneous Electrical Stimulation. 2008 30th Annual International Conference of the IEEE Engineering in Medicine and Biology Society, Vancouver, 20-25 August 2008, 5684-5687. 
https://doi.org/10.1109/IEMBS.2008.4650504

[25] Elbohoty, A.E.H., Abd-Elrazek, H., Abd-El-Gawad, M., Salama, F., El-Shorbagy, M. and Abd-El-Maeboud, K.H.I. (2012) Intravenous Infusion of Paracetamol versus Intravenous Pethidine as an Intrapartum Analgesic in the First Stage of Labor. International Journal of Gynecology \& Obstetrics, 118, 7-10.

https://doi.org/10.1016/j.ijgo.2012.01.025

[26] Porreca, F. and Ossipov, M.H. (2009) Nausea and Vomiting Side Effects with Opioid Analgesics during Treatment of Chronic Pain: Mechanisms, Implications, and Management Options. Pain Medicine, 10, 654-662.

https://doi.org/10.1111/j.1526-4637.2009.00583.x 